\title{
Quality Management through Six Sigma Method
}

\author{
Durairaj V. P, J. Manikandan, R. Sharavanan
}

\begin{abstract}
This project is a pure analytical research to manage the product in quality in mass production centre to reduce the rejections with modern techniques of six sigma approach. Now-a-days the mass production centre reducing the rejections in PPM level in parts per million instead of percentage. One percentage rejection makes only one part per hundred numbers, legally it shows very less but in mass production centre it is ten thousand parts per million which is very huge quality. To reduce the rejections by PPM level, six sigma approach is the best and approved method in any kind of product that too in Automobile accessories manufacturing area.
\end{abstract}

This project deals with a mass production automobile accessories manufacturing company to analyze, their rejections and reduce them by PPM level. Giving suggestions with proper evidence to the management to implement the facilities to improve the quality of the product. SUPER AUTO FORGE LTD, Medavakkam given their rejection and production quality of recent month to analyze, with their product and different types of flaws. We have analyzed the various process and the rejections generated during the process. Various design of experiment and quality tools applied in analysis and them to maintain for that visit to the company to get the evidence in physical.

Keywords: Quality management, Six sigma

\section{INTRODUCTION}

To improve business and improve profitability, a competitive company must placed in place the best feasible techniques and procedures to guarantee the performance of its products or facilities. Customer satisfaction is the first task and primary goal of any industry. So it is necessary to know well and aware of the importance of the customer and their need particularly the quality of the products or services. The Six Sigma methodology is used to find out the solution of the reduction in Internal Rework \& Rejection in process of piston to 100 PPM. The solution for the statement of the problem is found that defects are not cause by CNC machining and Rough Grinding by various QC tools \& DOEs through Six Sigma approach [1-6].

\section{SIX SIGMA}

The SIX SIGMA method is one of the most commonly used business models for this kind of quality control and leadership. The SIX SIGMA method is a business model or philosophy aimed at continuing customer-based brand improvement.

The SIX SIGMA strategy also focuses on improving performance by inspecting flaw avoidance products or

Revised Manuscript Received on August 22, 2019.

Durairaj V.P, Department of Mechanical Engineering, Bharath Institute of Higher Education and Research, Chennai, Tamilnadu, India.

J. Manikandan, Department of Mechanical Engineering, Bharath Institute of Higher Education and Research, Chennai, Tamilnadu, India.

R. Sharavanan, Department of Mechanical Engineering, Bharath Institute of Higher Education and Research, Chennai, Tamilnadu, India. facilities. This SIX SIGMA model emphasizes the execution of wide-ranging business operations to motivate greater efficiency for the assigned staff and teams. The SIX SIGMA method proves to be very useful in ensuring that product quality is accomplished as a quicker pace and continuously maintaining customer satisfaction. This method is accomplished through consistently excellent results to measure norms and expectations up to the target clients [7-9].

This contributes to greater viability and profitability for the business that utilizes the SIX SIGMA APPROACH to the six Sigma QUALITY IMPROVEMENT stands for Six standard deviation from average. Six Sigma comparable to Zero Defect (ZD) is Philip Crosby's suggested philosophical benchmark or level of excellence.

Six Sigma methodology offers the methods and instruments for enhancing capacity and reducing any system flaws. It was began in its manufacturing department by Motorola in 1987. Six Sigma strives for perfection. It allows for only 3.4 defects per million opportunities. Six Sigma improves the process performance, decrease variation and maintains consistent quality of the process output. Six Sigma leads to defect reduction and improvements in profits, product quality and customer satisfaction [10-12].

A efficiency objectives representing 3.4 flaws for millions of chances of making one. A collection of instruments and techniques used for product, process and service improvement or layout. A statistical measure showing the amount of standard deviations within the hopes of the client. A fact-based, rigorous approach to managing a company and its procedures. A implies of enhancing understanding of client requirements, measuring efficiency and improving company [13-18].

\section{METHODOLOGY}

This project "Quality Management Through Six Sigma Approach" is analytical. In this project we are going to analyze the problem and then we are going to reduce those problem by using Six Sigma method. For this project we went to SUPER AUTO FORGE PVT.LIMITED and we analyze this project by using DMAIC (Define,Measure,Analyze,Improve,Control) method. Firstly we get the data from the from the company that in which process they are getting most of the defect and then we analyze that in Grinding process they are getting defect in a large ammount.We went to the company and finished our project by using SIX SIGMA. [19-21]

\section{OBJECTIVE}

The objectives of this thesis are :

- To utilize six sigma methodology in performing the study

- To study the outer diameter of pistons dimension rejection trend by utilizing QC tools as 
the identified grinding machine.

- To identify the root causes of the OD rejects \&

- To recommend actions to eliminate rejects to sigma levels. If you are using Word, use either the Microsoft Equation Editor or the MathType add-on (http://www.mathtype.com) for equations in your paper (Insert | Object | Create New | Microsoft Equation or MathType Equation). "Float over text" should not be selected [22].

\section{RESULTS}

Six Sigma is great for company, providing company outcomes that can speed development, cut expenses, and eventually provide stakeholders with exceptional revenues. Six Sigma procedures have been implemented by manufacturing industries, healthcare and many more sectors to enhance efficiency and offer unparalleled product, service and service quality and efficiency to clients. This document describes the methodology of Six Sigma and the best practices for implementing the same throughout the company.

\section{CONCLUSION}

Six sigma level concept explained to basic machine operators before taking the project in super auto forge Pvt. Ltd., A team organization from AGM-QA to grinding machine tool operator level to achieve the target as zero defect quality product producing or at least 100 PPM level (BENCH MARK).

Discussed with the team about six sigma approach and training conducted the methodology of six sigma, by which any problem solved by systematically and controlled consistently. this project title "QUALITY MANAGEMENT THROUGH SIX SIGMA APPROACH " is taken in super auto forge Pvt. Ltd., located in medavakkam, chennai -600100. this project has focused on the major defect during the processing of grinding of piston outer diameter by centre less grinding. By DEFINE, the defect location is found in final grinding process. MEASURE phase has got the current level operating situation through control chart of operational sequence. ANALYZE the problem by selected design of experiments and some of QC tools. IMPROVE process by repair and replace of some component \& accessories of grinding machine and total productive maintenance (TPM) has been carried out for the major problem occurring machine and time frame plotted for TPM to all piston related machine tool. To CONTROL \& achieve the target, 100\% OD snap gauge inspection in $\mathrm{CNC}$ turning process \& run chart implemented for rough and final grinding process have introduced and monitored. this project is concluded by achieve 100 PPM level defects reduced from 3100 PPM level by constant monitoring \& six sigma approach.

\section{REFERENCES}

[1] Tatikonda, N.C. \& Naveenchandran, P. 2019, "The behaviour of a compression ignition engine under the influence of diesel and microalgae biodiesel blends", International Journal of Mechanical and Production Engineering Research and Development, vol. 9, no. 4, pp. 447-456.

[2] Tatikonda, N.C. \& Naveenchandran, P. 2019, "An experimental assessment on the impact of injection pressure on the characteristics of a diesel engine powered with the blend of diesel and microalgae biodiesel", International Journal of Engineering and Advanced Technology, vol. 8, no. 6, pp. 3284-3291.

[3] Karthikeyan, S., Raman Balasubramanian, S.R., Ramesh, B., Raghul, S. \& Sathish Kumar, S. 2019, "The automatic solar tracker chronicles", International Journal of Recent Technology and Engineering, vol. 8, no. 1 , pp. 312-315.

[4] Hema, R., Sundararajan, M. \& Balaji, S. 2019, "Smartphone control robot with automatic firing gun", International Journal of Innovative Technology and Exploring Engineering, vol. 8, no. 9 Special Issue 3, pp. 625-627.

[5] Saritha, B., Chockalingam, M.P. \& Aswathy, M. 2019, "Degradation of anionic dye using Fe/Tio2 composite by photocatalysis", International Journal of Innovative Technology and Exploring Engineering, vol. 8, no. 9 Special Issue 3, pp. 788-791.

[6] Saritha, B., Maria Subashini, L. \& Aswathy, M. 2019, "Utilization of spent coffee grounds for compost production", International Journal of Innovative Technology and Exploring Engineering, vol. 8, no. 9 Special Issue 3, pp. 908-910.

[7] Fernando, J.K., Meikandaan, T.P. \& Hemapriya, M. 2019, "Better utilisation of bottom ash in coal fired thermal power station", International Journal of Innovative Technology and Exploring Engineering, vol. 8, no. 9 Special Issue 3, pp. 898-900.

[8] Kumar, K.S., Kiruthiga, K. \& Thendral, S. 2019, "Experimental analysis on fractional substitution of bond by utilizing rice husk cinder", International Journal of Innovative Technology and Exploring Engineering, vol. 8, no. 9 Special Issue 3, pp. 1163-1165.

[9] Vignesh, P., Madan, P., Mohankumar, D. \& Naveenchandran, P. 2019, "Optimization of four stroke c.i. engine performance by using statistical techniques (mathematical method)", International Journal of Recent Technology and Engineering, vol. 8, no. 2, pp. 1685-1691.

[10] Bharanidharan, S., Sathiyamurthy, K. \& Sheeba, B. 2019, "Using co-precipitation method determining synthesis and characterization of fe doped zinc oxide nanoparticles", International Journal of Innovative Technology and Exploring Engineering, vol. 8, no. 9 Special Issue 3, pp. 705-707.

[11] Jeevanandan, D. \& Vino, J.A. 2019, "Heat recovery from boiler blowdown water by using heat exchanger in thermal power plant", International Journal of Mechanical and Production Engineering Research and Development, vol. 9, no. 3, pp. 219-222.

[12] Rakesh, N.L., Balambica, V. \& Kannan, S. 2019, "Biogas extraction from waste orange peel by digestion process", International Journal of Mechanical and Production Engineering Research and Development, vol. 9 , no. 3, pp. 323-330.

[13] Meenakshi, C.M. \& Krishnamoorthy, A. 2019, "The mechanical characterization of mono and hybrid fiber reinforced composites using experimental and finite element analysis methods", International Journal of Mechanical and Production Engineering Research and Development, vol. 9, no. 3, pp. 189-196.

[14] Mohankumar, D., Prem Jayakumar, M., Sabarsish, R. \& Naveen Chandran, P. 2019, "Modeling and experimental investigation on centrifugal blower by computational fluid dynamics", International Journal of Mechanical and Production Engineering Research and Development, vol. 9, no. 3, pp. 331-340.

[15] Balambica, V., Deepak, V. \& Kumar, S. 2019, "Design and efficiency of an asymmetric gear", International Journal of Mechanical and Production Engineering Research and Development, vol. 9, no. 3, pp. 223-230.

[16] Manavalan, S., Balakrishnan, G. \& Ramasubramaniam, S. 2019, "An effect of cobalt oxide nano additive with biodiesel blends using cidi diesel engine", International Journal of Mechanical and Production Engineering Research and Development, vol. 9, no. 3, pp. 211-218.

[17] Golden Renjith Nimal, R.J., Sivakumar, M. \& Esakkimuthu, G. 2019, "An investigation on mechanical properties and microstructure of $\mathrm{mg} / \mathrm{al}$ alloys using zn interlayer during diffusion bonding", International Journal of Mechanical and Production Engineering Research and Development, vol. 9, no. 3, pp. 125-130.

[18] Hariharan, R., Raja, R. \& Vasu, S. 2019, "Mechanical and tribological behaviour of thin tan coating produced on AISI 1018 substrate by DC magnetron sputtering", International Journal of Recent Technology and Engineering, vol. 7, no. 6, pp. 591-598

[19] Manavalan, S., Rai, R., Kumar, R.R., Chaudhary, R.K. \& Chaudhary, S.K. 2019, "Impact of modified piston - A review", International Journal of Recent Technology and Engineering, vol. 8, no. 6, pp. 616-620.

[20] Manavalan, S., Gopi, A., Arivarasu, J., Abishek Ahi, A. \& Chandru, S. 2019, "Review on ceramic disc brake system", International Journal 
of Recent Technology and Engineering, vol. 7, no. 6, pp. 612-615.

[21] Sabarish, R. \& Jeya Kumar, M.P. 2019, "The design and analysis of piston - Steady state thermal analysis using "ansys"", International Journal of Mechanical and Production Engineering Research and Development, vol. 9, no. 3, pp. 197-204.

[22] Ravi, D. 2019, "CFD simulation of solar loading in car", International Journal of Mechanical and Production Engineering Research and Development, vol. 9, no. 3, pp. 231-236.

\section{AUTHORS PROFILE}

Durairaj V. P, Assistant Professor, Department of Mechanical Engineering, Bharath Institute of Higher Education and Research, Chennai, India

J. Manikandan, Assistant Professor, Department of Mechanical Engineering, Bharath Institute of Higher Education and Research, Chennai, India

R. Sharavanan, Assistant Professor, Department of Mechanical Engineering, Bharath Institute of Higher Education and Research, Chennai, India 